\title{
From the ICL2009 Conference Chair
}

The $12^{\text {th }}$ International Conference on Interactive Computer Aided Learning, ICL2009, which took place in the period 23-25 September 2009 in Villach, Austria, has attracted about 270 scientists and practitioners from 58 countries from Europe and worldwide.

This interdisciplinary conference was again focused on the exchange of relevant trends and research results as well as the presentation of practical experiences gained while developing and testing elements of interactive computer aided learning.

The conference was been organized by the Carinthia University of Applied Sciences, in collaboration and with support of partners

- IEEE Education Society

- European Learning Industry Group (ELIG)

- International E-Learning Association (IELA)

- European Institute of E-Learning (ElfEL)

- International Society of Engineering Education (IGIP)

- International Association of Online Engineering (IAOE)

- European Distance and E-learning Network (EDEN)

- European Federation for Open and Distance Learning

- European Association of Distance Teaching Universities

Keynote speakers have been:

- Kumiko Aoki, Professor at the National Institute of Multimedia Education, Japan

- Peter Dolog, Professor at the Department of Computer Science, Aalborg University, Denmark

- Kees-Jan van Dorp, European Association of Distance Teaching Universities (EADTU), Research Director

- Arthur Edwards, Professor at the University of Colima, Mexico

- Diem Ho, IBM, Member of the IBM Academy of Technology, Manager of University Relations

- Seth Norberg, Royal Institute of Technology; Consultant for the Intel Education Initiative, Stockholm, Sweden

- Paulo Wollinger, Director of Higher Education Accreditation, Ministry of Education Brazil

- Kristijan Zimmer, Head of Information Support Center, University of Zagreb, Croatia 
The high number of submissions (about 300 papers have been submitted) as well as the number of participants shows the great interest in this topic and the attractiveness of the conference venue..

The conference was assessed by the participants of 'high standard', providing a 'great number of constructive discussions' in a 'very agreeable work atmosphere' in the wonderful Conference Center of Villach.

The following selected papers, published in this iJET special issue, give a short insight into some of these years' topics.

Michael E. Auer

ICL Conference Chair 